\title{
Cécile Brochard, Esther Pinon (sous la direction de), La folie - Création ou destruction?
}

\section{Francesca Forcolin}

\section{(2) OpenEdition}

1 Journals

\section{Edizione digitale}

URL: https://journals.openedition.org/studifrancesi/4858

DOI: 10.4000/studifrancesi.4858

ISSN: 2421-5856

\section{Editore}

Rosenberg \& Sellier

\section{Edizione cartacea}

Data di pubblicazione: 1 avril 2012

Paginazione: 200-201

ISSN: 0039-2944

\section{Notizia bibliografica digitale}

Francesca Forcolin, «Cécile Brochard, Esther Pinon (sous la direction de), La folie - Création ou destruction?», Studi Francesi [Online], 166 (I | LVI) | 2012, online dal 30 novembre 2015, consultato il 19 novembre 2021. URL: http://journals.openedition.org/studifrancesi/4858 ; DOI: https://doi.org/ 10.4000/studifrancesi.4858

Questo documento è stato generato automaticamente il 19 novembre 2021.

\section{(c) $($ ) $\odot$}

Studi Francesi è distribuita con Licenza Creative Commons Attribuzione - Non commerciale - Non opere derivate 4.0 Internazionale. 


\title{
Cécile Brochard, Esther Pinon (sous la direction de), La folie - Création ou destruction?
}

\author{
Francesca Forcolin
}

\section{NOTIZIA}

CÉCILE BROCHARD, ESTHER PINON (sous la direction de), La folie - Création ou destruction?, Presses Universitaires de Rennes, Rennes, 2011, pp. 189.

1 Gli articoli che compongono il volume nascono dalla giornata di studi svoltasi nell'aprile 2010, organizzata dalla Scuola Dottorale di Nantes, diretta da Guy Saupin, e dall'équipe AMO, diretta da Philippe Forest. Il tema è quello della follia, intesa come tappa proteiforme nel percorso della creazione artistica e, in particolare, letteraria. La follia avrebbe, infatti, due versanti: l'uno, il versant noir, il lato inquietante e maledetto, la passione devastatrice e la follia criminale; l'altro, il visage bouffon, il lato comico, carnevalesco. Direbbe Foucault che tale ambiguità è elemento caratterizzante della follia, al punto che risulterebbe ostico considerarla come risorsa fertile della scrittura, fonte d'ispirazione, o piuttosto forza distruttiva, generatrice di disordine. È su questo punto che si interrogano gli undici contributi che compongono l'opera, suddivisa in quattro parti d'impianto cronologico, e introdotte dalla Préface di Cécile BROCHARD e Esther PINON (pp. 9-13). Come viene concepita la follia nel corso dei secoli, da un'era culturale all'altra? È una minaccia per la scrittura, confinata al mutismo, o piuttosto è il silenzio stesso che ne fa la ricchezza? E il folle, è il delirante, il demente, o piuttosto il genio, mitizzato e fonte di riscritture come lo sono il visionario Don Chisciotte e Orlando?

2 La «Première Partie», o La folie et ses mythes: pérennité et subversions, analizza due miti, la "nef des fous"-motivo grottesco medievale d'ispirazione religiosa, che consiste nell'isolare su una barca i malati mentali - e il mito di Orlando, fino alla sua riscrittura 
nel XVII secolo con Quinault (La nef des fous ou la "traversée". D'un 'topos' des origines au romantisme, di Dominique PEYRACHE-LEBORGNE, pp.15-36; Du 'Roland furieux' au 'Pierrot furieux': la folie comme motif de création, di Emmanuelle souPIZET, pp. 37-52; De la folie à la rage: Roland sur la scène parodique de 1694 à 1755, di Julianne CoIGNARD, pp. 53-73).

(uxième partie», o La folie au XIXe siècle: du romantisme au symbolisme, si concentra in particolare sulle opere di Musset, Balzac, e su autori fin de siècle quali Maupassant, Huysmans, Mann. La follia si svela in immagini dionisiache, visioni fantastiche e macabre, fantasie in cui si mescolano Eros e Thanatos, in orge, incubi notturni, una scrittura frenetica dell'eccesso. Un delirio tipicamente romantico, che coincide con un'emergente curiosità scientifica verso le malattie mentali, e la nascita di trattati medici e psichiatrici. Il capitolo IV, Les fantaisies de Dionysos. Frénésie et folie chez Musset, è di Sylvain LEDDA (pp.77-88); segue il capitolo V, Fous balzaciens, di Patrick BERTHIER (pp. 89-100); e il VI, Le fou, l'alchimiste de l'image, di Julien ROIRARD (pp. 101-113).

La «Troisième partie, o Auteurs "fous"; pathologie et inventivité», s'interroga invece su alcuni autori del ' 900 , quali Rodanski, Crevel, Sartre. Qui, motivo centrale è la «folie qu'on enferme», la patologia che separa delirio e visione, genialità e follia, quella vertigine tanto ricercata dai Surrealisti che ne fanno il motore principale della creazione, fonte d'ispirazione poetica. Nelle prime opere di Sartre, la scrittura si svela come strumento terapeutico, strategia e droga per trionfare sulla depressione, malinconia, malattia. Lo scrittore si pone come un animale nella gabbia della pazzia, che cerca rifugio nell'immaginazione (La chambre). Pierre BRUNEL firma l'articolo intitolato Stanislas Rodanski: la folie qu'on enferme (pp.117-134); segue"Je ne m'arrete plus quand je vois la folie". Approche surréaliste de la folie dans l'oeuvre de René Crevel, di Marc VERLYNDE (pp.135-146); e Autoportraits de Sartre en écrivain fou, di Yves ANSEL (pp. 147-160).

5 Chiude la "Quatrième partie», intitolata Folie et politique: oppressions et libérations, riflessione sul rapporto tra follia e potere, dittatura, delirio di potenza: nelle opere di Montalbán, Bastos, Márquez, Cau e Busset il primo contributo (La folie du pouvoir: vanité, ostracisme et autodestruction di Cécile BROCHARD, pp.163-176); nell'opera labirintica di Boris Diop il secondo (L'imaginaire du labyrinthe et la folie dans le roman de Boubacar Boris Diop, di Larissa DogBo BozouzouA, pp. 177-189). 